\title{
Refractory Oral Lichen Planus with Twenty Nail Dystrophies in Association with Rare Retroperitoneal Inflammatory Myofibroblastic Tumor: A Case Report
}

\author{
Sijapati KS ${ }^{1 *}$, Agrawal $\mathrm{S}^{2}$, Pokhrel $\mathrm{S}^{3}$, Shah $\mathrm{N}^{3}$ and Pant $\mathrm{AR}^{4}$ \\ ${ }^{1}$ Senior resident, BP Koirala Institute of Health Science, Dharan, Nepal \\ ${ }^{2}$ Professor; Department of Dermatology and Venereology, BP Koirala Institute of Health Science, Dharan, Nepal \\ ${ }^{3}$ Associate professor, Department of Pathology, BP Koirala Institute of Health Science, Dharan, Nepal \\ ${ }^{4}$ Associate Professor; Department of Radiology, BP Koirala Institute of Health Science, Dharan, Nepal
}

Submission: April 17, 2020; Published: April 29, 2020

*Corresponding author: Sijapati KS, Senior resident, BP Koirala Institute of Health Science, Dharan, Nepal

\begin{abstract}
Lichen planus (LP) is a chronic inflammatory T cell mediated autoimmune disease with oral involvement in 30\% - $70 \%$ cases. Oral LP has been found to be associated with a variety of triggering factors, including neoplasia but it is difficult to determine whether the association is causal or serendipitous. We report here a child with refractory oral LP with twenty nail dystrophies, in whom a rare retroperitoneal inflammatory myofibroblastic tumor was diagnosed. Although the association of LP and neoplasia is uncommon, we emphasize the significance of considering neoplasia in patients with severe oral LP that is refractory to treatment.
\end{abstract}

Keywords: Oral LP; T cell mediated autoimmune disease; Neoplasia

Abbreviations: LP- Lichen Planus; IMT- Inflammatory Myofibroblastic Tumor; CECT- Contrast-Enhanced Computed Tomography; SMA- Smooth Muscle Actin

\section{Introduction}

Lichen planus (LP) is an idiopathic, chronic inflammatory T cell mediated autoimmune disease, affecting the skin and mucus membranes. Oral involvement occurs in 30\% -70\% of cases and has been found to be associated with a variety of triggering factors, including neoplasia but it is difficult to determine whether the association is either causal or purely serendipitous [1]. Oral LP is the most common type of LP associated with nail LP and twenty nail dystrophies is seen in $10 \%$ of patients affected by nail lichen planus (LP) [2,3]. We report here a child, with refractory oral LP with twenty nail dystrophies in whom neoplasm (inflammatory myofibroblastic tumor- IMT) was diagnosed.

\section{Case Report}

A 12-year-old boy was referred by a Dermatologist a nonresponding case with clinical diagnosis of oral LP for second expert opinion. The patient had received betamethasone oral mini pulse for six months, but there was no any subjective and objective improvement. At presentation he had the chief complaint of violaceous discoloration of lips, painful oral erosions and dystrophy of all fingers and toe nails for $21 / 2$ years. The patient was admitted in Dermatology ward, where detailed history of the patient was reviewed and a history of intermittent abdominal pain for two and half years was revealed. He used to experience intermittent burning to cramping abdominal pain without bloating every two to three days and all symptoms were in remission after he buckled both legs, however, the pain returned a few minutes later. The patient did not have symptoms of fever, nausea, vomiting, weight loss, bowel obstruction or other discomfort and he did not receive treatment to relieve these symptoms prior to admission. There was no history of any fluid filled skin lesions, drug intake, use of dental amalgam and constitutional symptoms prior to the 
appearance of lesions. No similar family history. Per abdominal examination was normal. Examination of the lips and oral cavity revealed violaceous plaques involving whole of both upper and lower lip along with ill to well defined irregular erosions of size 0.5 $\mathrm{cm}$ to $0.3 \mathrm{~cm}$ over buccal mucosa, tongue and soft palate (Figure 1). On examination of nails, dystrophy of all finger nails and toe nails were observed (Figure 2).

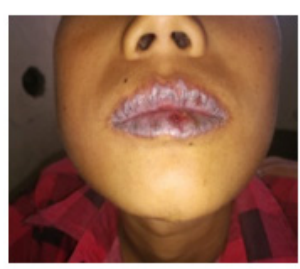

(a)

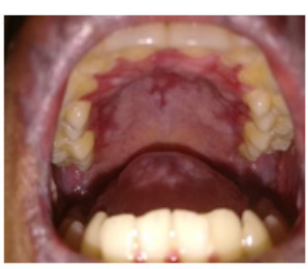

(b)

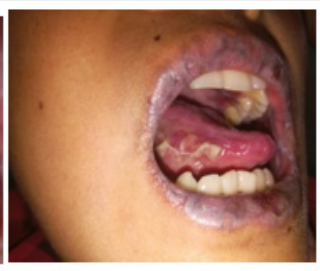

(c)

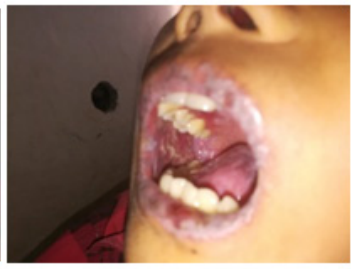

(d)

Figure 1: Baseline photographs. a) Violaceous plaque over lips. b), c) \&d) Irregular erosions over the palate, tongue and buccal mucosa.

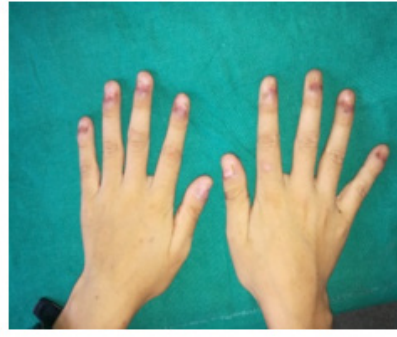

(a)

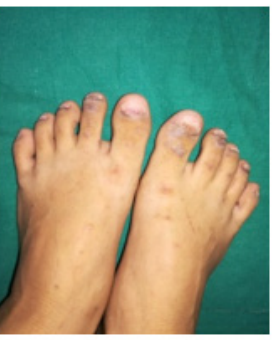

(b)

Figure 2a \& 2b: Twenty nail dystrophy.

\section{Investigations}

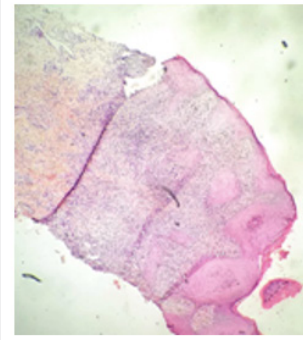

(a)

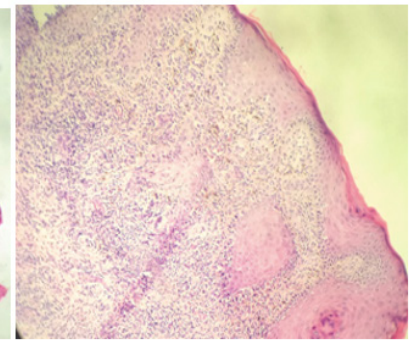

(b)

Figure 3: Histopathological examination from lower lip: a) stratified squamous epithelium, focal parakeratosis, irregular acanthosis, mild spongiosis with basal vacuolar degeneration at few areas $(4 \times 1)$. b) Dense inflammatory cell infiltrate predominantly in upper dermis comprising of lymphocytes, plasma cells, neutrophils and histiocytes $(10 \times 1)$.

Hematology and biochemistry reports were normal. Biopsy for histopathological examination from the lower lip was consistent with oral LP (Figure 3). For abdominal pain, ultrasonography of the abdomen and pelvis was done which showed, a welldefined heterogenous hypoechoic mass lesion with few foci of calcification within and with minimal internal vascularity abutting the hilar surface spleen and upper pole of left kidney. For further evaluation CECT (contrast-enhanced computed tomography) abdomen and pelvis was done, which revealed large moderately enhancing lesion of size $11.5 \mathrm{~cm}$ x $8.5 \mathrm{~cm}$ with central 


\section{Juniper Online Journal of Dermatology \& Cosmetics}

non-enhancing hypodense area (likely necrotic area) and foci of calcification within in left paravertebral region (extending from upper border of L1 up to upper border of T8 vertebral body) with thickened surrounding tissue and a coarse focus of calcification adjacent to it and sclerosis of T9, T10, T11 vertebral bodies(more on left), likely to be neuroblastic tumor (Figure 4) and suggested for cytohistopathological correlation. Trucut biopsy of the left suprarenal retroperitoneal mass showed features of low-grade spindle cell tumor of fibrohistiocytic origin (Figure 5) and immunohistochemistry showed tumor cells positive for viamentin and SMA (Smooth muscle actin) (Figure 6) and the features were suggestive of inflammatory myofibroblastic tumor.

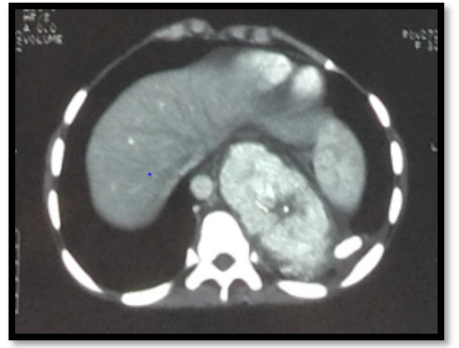

(a)

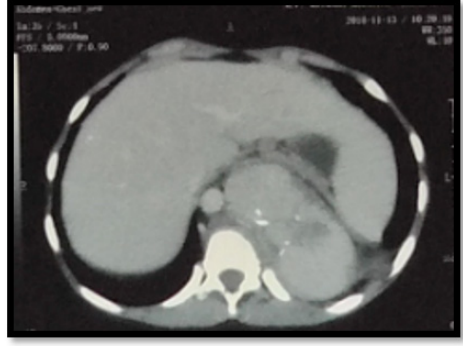

(b)

Figure 4: Abdominal CECT: a) Baseline, b) After 6 months from baseline Large moderately enhancing lesion $(11.5 \mathrm{~cm} \times 8.5 \mathrm{~cm})$ with central non-enhancing hypodense area and foci of calcification within left paravertebral region with thickened surrounding tissue and a coarse focus of calcification adjacent to it.

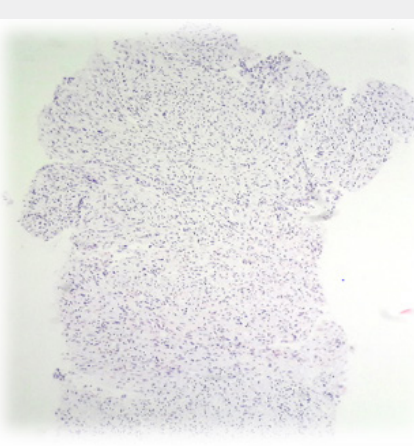

(a)

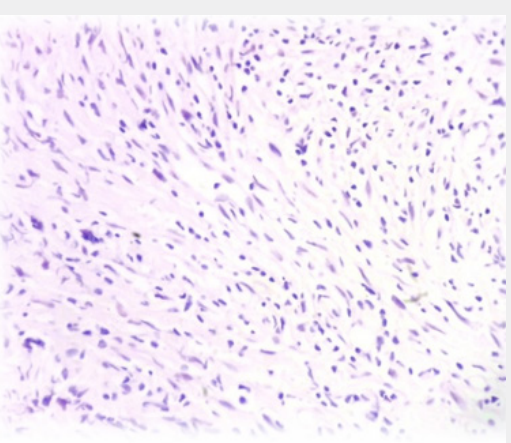

(b)

Figure 5: Histopathological examination of retroperitoneal mass: a) Bit of fibrocollagenous tissue $(4 \times 1)$. b) Proliferation of spindle shaped cells in short fascicles as well as in haphazard pattern showing mild atypia admixed with lymphocytes $(40 \times 1)$.

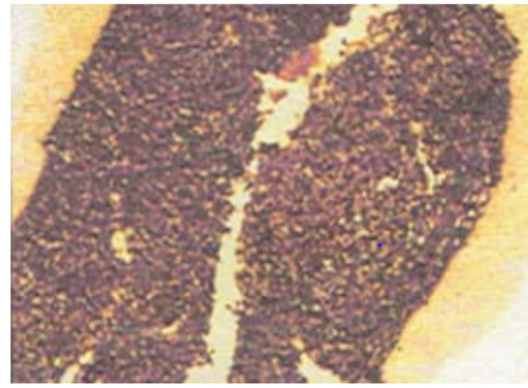

(a)

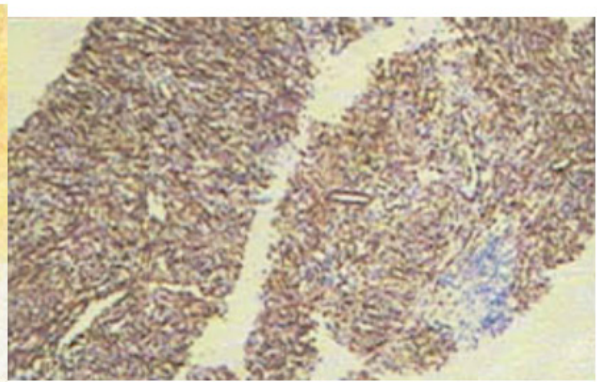

(b)

Figure 6: Immunohistochemistry: Tumor cells positive for a) Viamentin and b) SMA 


\section{Juniper Online Journal of Dermatology \& Cosmetics}

\section{Treatment}

After a multidisciplinary discussion, 6 courses of Methotrexate (20 mg), Placitin (35 mg) and Dexamethasone 16mg in two divided doses was administered intravenously once a month, with Triamcinolone acetonide $0.1 \%$ oral paste and ointment Tacrolimus $0.1 \%$ for oral LP. After receiving [3] courses of chemotherapy, the patient showed drastic improvement as the oral lesions had healed by up to $90 \%$ (Figure 7) but the tumor did not decrease in size which was confirmed by abdominal CECT (Figure 8). Then, the patient underwent left thoraco-laparotomy with excision of mass followed by a biopsy. He has been put on a periodic recall so that his condition can be monitored.
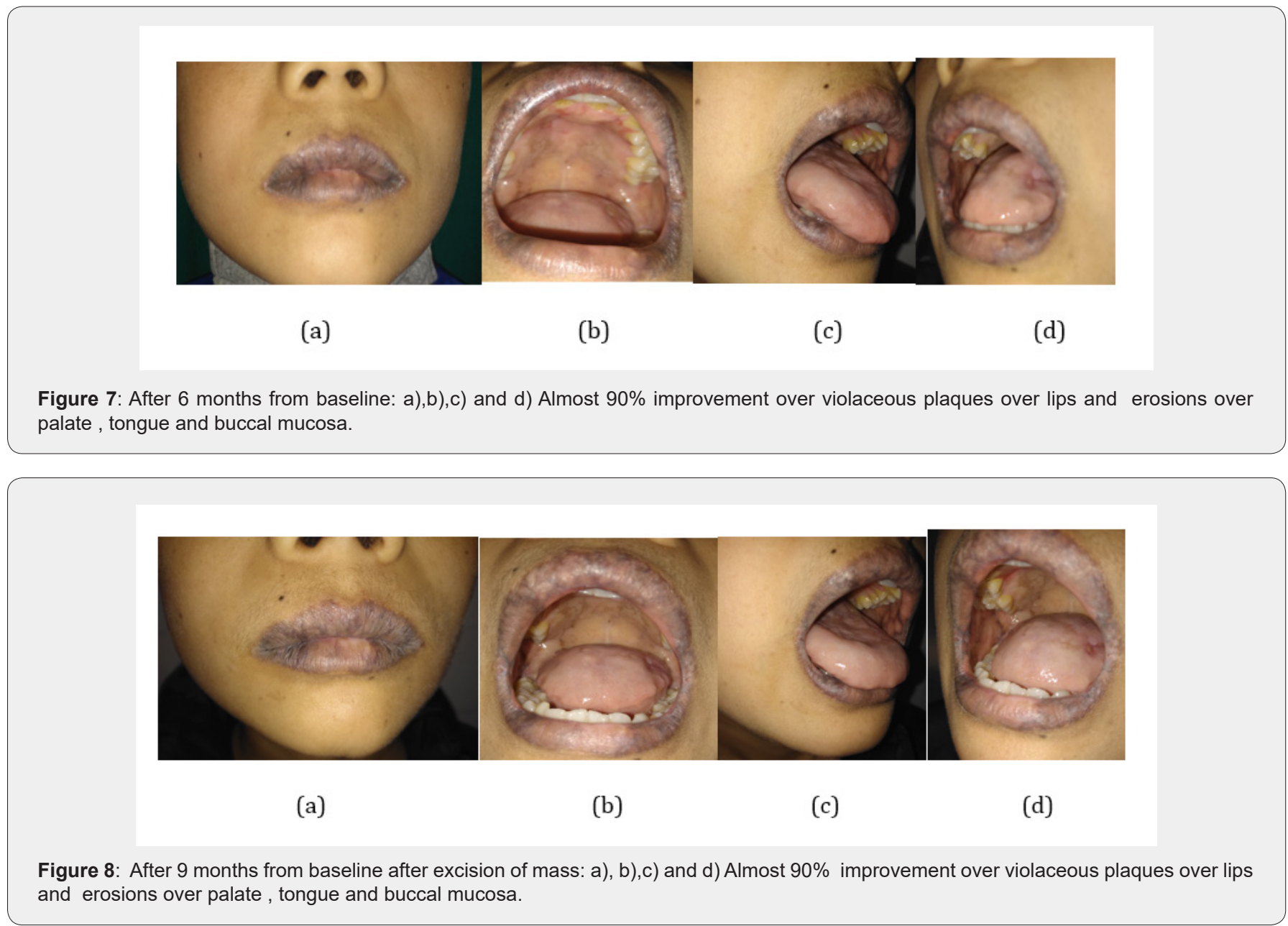

\section{Discussion}

LP is an idiopathic inflammatory skin disease affecting the skin and mucosal membranes, which has a chronic course with relapses and periods of remission [1]. It is a T-cell-mediated autoimmune disease, likely targeting the basal keratinocytes, which can be triggered by a variety of situations, including viruses, drugs and contact allergens. Mucous membrane lesions occur in $30-70 \%$ of cases with LP. Oral LP is the most common type of LP associated with nail LP and twenty nail dystrophies is seen in $10 \%$ of patients affected by nail lichen planus (LP) [2,3]. Retroperitoneal IMTs are extremely rare tumors with low grade malignant potential [4]. Similar to LP the exact etiology of the tumor is still not completely known, but researchers have suggested that apart from trauma, surgery and inflammation, viral infection such as Epstein-Barr virus or Human Herpes virus are triggering factors of IMT [5]. Thus, viral infections are common trigger for both LP and IMTs.

An association of LP with malignancy is controversial. LP has been described in association with gastric cancer, lymphosarcoma, neuroblastoma, craniopharyngioma and pararenal malignancy whereas oral LP has been reported in association with thymoma and Castleman's tumor [6]. There are reports of regression of oral LP lesions following resection of the primary tumor (thymoma) [7]. Tumor antigens may lead to the production of an autoimmune response that may be preferentially of a humoral nature in paraneoplastic pemphigus or predominantly cell-mediated in neoplasia-induced LP. As in paraneoplastic pemphigus, neoplasia-induced LP may not exactly parallel the course of the underlying tumor in all cases and lesions may continue after the 
underlying neoplasia is no longer evident [8]. Patients with oral LP have impaired lymphocyte and neutrophil function along with expression of neoantigens on $\mathrm{T}$ cells that function as receptors for laminin, fibronectin, and collagen [2,3]. Thus, it is conceivable that an underlying neoplasm may induce some of the changes in oral LP.

\section{Conclusion}

Although the association of oral LP and neoplasia is uncommon, clinicians should consider neoplasia (either benign or malignant) in patients with severe, refractory oral LP. Thus, refractory oral LP may be considered as a paraneoplastic marker, especially if the lesions precede or occur concurrently with the neoplasia.

\section{References}

1. Piguet V, Stephen M Breathnach, Cleach LL (2016) Lichen planus. Rook's text book of Dermatology, $9^{\text {th }}\left(\mathrm{Ed}^{\mathrm{n}}.\right)$, Oxford, Wiley Blackwell, UK, p 37: 1-20.
2. Piraccini BM, Saccani E, Starace M, Balestri R, Tosti A (2010) Nail lichen planus: Response to treatment and long term follow-up. Eur J Dermatol 20(4): 489-496.

3. Peluso AM, Tosti A, Piraccini BM, Cameli N (1993) Lichen planus limited to the nails in childhood: Case report and literature review. Pediatr Dermatol 10(1): 36-39.

4. Leon CJ, Castillo J, Mebold J, Cortez L, Felmer R (2006) Inflammatory myofibroblastic tumor of the stomach: an unusual complication after gastrectomy. Gastrointest Endosc 63(2): 347-349.

5. Xiang J, Liu X, Wu S, Lv Y, Wang H (2012) Multiple inflammatory myofibroblastic tumor of the duodenum: case report and literature review. J Gastrointest Surg 16(7): 1442-1445.

6. Bobbio A, Vescovi P, Ampollini L, Rusca M (2007) Oral erosive lichen planus regression after thymoma resection. Ann Thorac Surg 83(3): 1197-1199.

7. Calista D (2001) Oral erosive lichen planus associated with thymoma. Int J Dermatol 40(12): 762-764.

8. Helm TN, Camisa C, Valenzuela R (1992) Perplexing parlance of paraneoplastic pemphigus. JAMA 268: 602-603.

\section{Your next submission with Juniper Publishers will reach you the below assets}

- Quality Editorial service

- Swift Peer Review

- Reprints availability

- E-prints Service

- Manuscript Podcast for convenient understanding

- Global attainment for your research

- Manuscript accessibility in different formats (Pdf, E-pub, Full Text, Audio)

- Unceasing customer service

Track the below URL for one-step submission https://juniperpublishers.com/online-submission.php 